\title{
Molecular characteristics of the H9N2 avian influenza viruses in live poultry markets in Anhui Province, China, 2013 to 2018
}

\author{
Shuxia Zhang ${ }^{1}$ | Jun-Ling $\mathrm{Yu}^{2}$ | Lan $\mathrm{He}^{2}$ | Lei Gong ${ }^{3}$ | Sai Hou ${ }^{3}$ | \\ Meng Zhu ${ }^{3}$ | Jia-Bing Wu ${ }^{3}$ | Bin Su${ }^{2}$ | Jia Liu ${ }^{1}$ | Guizhen $\mathrm{Wu}^{1}$ | Jun $\mathrm{He}^{2}$
}

\begin{abstract}
${ }^{1}$ National Institute for Viral Disease Control and Prevention, China Center for Disease Control and Prevention, Beijing, China

${ }^{2}$ Department of Microbiological Laboratory, Anhui Provincial Center for Disease Control and Prevention, Key Laboratory for Medical and Health of the 13th Five-Year Plan in Anhui Province, Hefei, China

${ }^{3}$ Department of Acute Infectious Disease Prevention, Anhui Provincial Center for Disease Control and Prevention, Hefei, China

\section{Correspondence}

Jun He, Department of Microbiological Laboratory, Anhui Provincial Center for Disease Control and Prevention, Key Laboratory for Medical and Health of the 13th Five-Year Plan in Anhui Province, Hefei 230601, China.

Email: heliosking@sina.com

Funding information

Scientific Research Projects of the Health and Family Planning Commission of Anhui Province in 2017 [2017jk004,2017jk005], Grant/Award Number: 2; the Chinese National Science and Technology Major Project for Important Infectious Diseases Control and Prevention [Grant No. 2018ZX10101002], Grant/Award Number: 1
\end{abstract}

\begin{abstract}
Background and Aims: H9N2 subtype avian influenza virus (AIV) has low-pathogenicity but causes respiratory symptoms and drop in egg production in chicken with long-term virus shedding, resulting in great economic losses due to high mortality related to secondary infection with other pathogens. In recent years, H9N2 viruses have been posing a threat to public health, causing human infection in China. Compared to studies on other AIV subtypes, there are relatively few studies on the pathogenic mechanism of the H9N2 virus in mammals. H9N2 subtype AIV has been circulating worldwide in many avian species and transmitting with high efficiency in poultry. It can provide internal genes for other subtypes to produce new viruses, causing a pandemic risk. It is important to carry out long-term surveillance and pathogenic characteristics of the H9N2 virus. In this study, we conducted environmental surveillance of live poultry markets in Anhui province from 2013 to 2018 , and 33 representative environmental isolates were selected and studied systematically.

Methods: The genomic RNA of Anhui H9N2 isolates was subjected to RT-PCR amplification followed by sequencing analysis.

Results: Thirty-three strains were isolated from the embryonated eggs of specificpathogen-free chickens. Phylogenetic analysis indicated that h9.4.2.5-like H9N2 viruses were predominant during 2013-2018 and acquired multiple specific amino acid mutations that may have increased their affinity for mammals and enhanced their infectivity and transmissibility. Additionally, six internal genes of H9N2 clustered together with the novel human-lethal reassortant viruses, such as the lowpathogenicity H7N9, H10N8, and Anhui H5N6 viruses, and even HPAI H7N9.

Conclusion: Because H9N2 viruses may be the donors of internal genes that lead to the generation of novel reassortant viruses with enhanced pathogenicity in Anhui province, continuous environmental surveillance of live poultry markets, a key source of reassorted H9N2 and other avian influenza viruses, is of great importance.

\section{KEYWORDS}

avian influenza, H9N2, live poultry markets, molecular characteristics, phylogenetic analysis
\end{abstract}

This is an open access article under the terms of the Creative Commons Attribution-NonCommercial-NoDerivs License, which permits use and distribution in any medium, provided the original work is properly cited, the use is non-commercial and no modifications or adaptations are made.

(c) 2021 The Authors. Health Science Reports published by Wiley Periodicals LLC. 


\section{1 | INTRODUCTION}

Avian influenza viruses (AIVs) can be divided into two broad categories: highly pathogenic avian influenza viruses (HPAIVs), and low pathogenic avian influenza viruses (LPAIVs), based on their pathogenicity in chickens and molecular characterization of the hemagglutinin (HA) protein. H9N2 AIVs, the subject of this study, have become endemic in poultry across much of Asia, the Middle East, and West and North Africa. ${ }^{1,2}$ In the mid-1990s, H9N2 AIV was first reported in chickens in Guangdong province of China, and subsequently became epidemic nationwide. ${ }^{3}$ At present, the poultry-adapted H9N2 AIVs are a major threat to not only poultry health but also human health, as some of the H9N2 lineage AIVs are zoonotic., ${ }^{1,4,5}$

To prevent H9N2 AIV infection in chickens, over 20 different commercial vaccines are used in China, and these vaccines are frequently updated. ${ }^{3}$ Unfortunately, H9N2 AIVs continue to persist in chickens, even in vaccinated chicken flocks, which is possibly due to an antigenic drift. ${ }^{6-8}$ Owing to the potential pressure of antigenic drift in poultry-adapted H9N2 AIVs, a large number of variant viruses evade the host's neutralizing antibodies.

Not only does antigenic drift lead to the emergence of variant viruses, but also the exchange of gene segments among different virus particles via gene reassortment generates a large number of novel viral descendants. ${ }^{9}$ H9N2 AIVs are often found co-circulating in poultry with other AIV subtypes such as $\mathrm{H} 5$ and $\mathrm{H} 7$ HPAIVs. ${ }^{10}$ Like other AIVs, H9N2 is prone to gene reassortment, which can affect host specificity, virulence, and pathogenicity. Live poultry are host to cocirculating subtypes of AIVs, while live poultry trading may influence the transmission of AIVs. ${ }^{11}$ Live poultry markets (LPMs), which are a key link in live poultry trading, require close monitoring. H9N2 AIVs may act as donors of genes to other AIVs such as H5N1, H5N6, H7N9, and H1ON8, which are responsible for high mortality rates in humans. ${ }^{1,12-14}$ Based on this information, it was crucial to investigate the molecular characteristics and genetic reassortment of H9N2 AIVs isolated from LPMs to assess whether these viruses possess the ability to infect and transmit to a new host.

\section{2 | MATERIALS AND METHODS}

\subsection{Sample collection}

Between 2013 and 2018, AIV surveillance according to the China CDC guidelines was conducted in Anhui province. Environmental samples from LPMs were collected, which included poultry drinking water, feces, wipes from the surfaces of cages, and boards used for the slaughtering of birds. These samples were stored in a viral transport medium composed of $15 \mu \mathrm{g} / \mathrm{mL}$ amphotericin $\mathrm{B}$, 100 units $/ \mathrm{mL}$ penicillin $\mathrm{G}, 50 \mu \mathrm{L} / \mathrm{mL}$ streptomycin, and $1 \%$ bovine serum albumin in Hank's balanced salt solution $(\mathrm{pH}$ 7.4). Under refrigeration, these sample were transferred to the Laboratory of Influenza Surveillance immediately, where they were stored prior to further examination.

\subsection{Virus isolation and identification}

Viruses were propagated in specific-pathogen-free (SPF) chick embryonated eggs, and then these eggs were incubated for $72-96$ hours at $37^{\circ} \mathrm{C}$. The collected allantoic fluids were subjected to a hemagglutination assay with $1 \%$ turkey red blood cells (TRBCs). The HA-positive samples were further subtyped by real-time RTPCR using 16 sets of $\mathrm{HA}(\mathrm{H} 1-\mathrm{H} 16)$ primers and 9 sets of neuraminidase (NA) (N1-N9) primers designed by the Chinese National Influenza Center (CNIC).

\section{3 | Viral RNA extraction and RT-PCR}

The HA-positive allantoic fluid was used for viral RNA extraction using a High Pure Viral Nucleic Acid Kit according to the manufacturer's instructions (Roche, Mannheim, Germany). Reverse transcription was performed with the Uni12 primer (5'-AGCAAAA GCAGG-3') and the RevertAid First-Strand cDNA Synthesis Kit (Fermentas, Canada). cDNAs of the eight segments were then amplified with gene-specific primers designed by the CNIC. All experiments were conducted in accordance with a previously published study. ${ }^{15}$

\subsection{Genome sequencing and phylogenetic analysis}

The PCR products were purified with a Wizard DNA Clean-Up System (Promega), then sequenced using the BigDye Terminator v3.1 Cycle Sequencing Kit (AB), and analyzed with an $A B I 3730 X L$ DNA analyzer. The BioEdit program (version 7.1.3.0) and ClustalW alignment algorithm (version 1.83) were initially used to compare and align nucleotide sequences. Phylogenetic trees were inferred using the neighborjoining method with MEGA software (version 7.0.26), and bootstrap values were tested with 1000 replications. ${ }^{16}$ The evolutionary distances were computed using the maximum composite likelihood method, and the units represent the number of base substitutions per site.

\section{5 | Molecular analyses}

The representative sequences used in this study for phylogenetic comparisons and molecular analyses were obtained from the Global Initiative on Sharing Avian Influenza Data (www.gisaid.org) and the GenBank database (www.ncbi.nlm.nih.gov). The Influenza Virus Sequence Annotation Tool (https://www.ncbi.nlm.nih.gov/genomes/ FLU/annotation/) was used to predict protein sequences encoded by the input sequences. The potential $\mathrm{N}$-glycosylation sites were predicted using the NetNGlyc 1.0 web server (http://www.cbs.dtu. $\mathrm{dk} /$ services/NetNGlyc/). By default, predictions were carried out only on the Asn-Xaa-Ser/Thr sequons. 


\section{3 | RESULTS}

\section{1 | Virus isolation and identification}

Between 2013 and 2018, a total of 5110 environmental samples were collected from the sampling sites for poultry-related environmental surveillance in Anhui province. Analysis revealed that 582 environmental samples were positive for the H9N2 AIVs. From these samples, we obtained 33 strains using SPF chick embryonated eggs (the H9N2 isolation rate was $5.67 \%$, Table S1). To further understand the molecular evolution of the H9N2 strains in different geographical locations, we selected all isolates from eight cities in Anhui province to construct a genetic evolutionary tree, including 16 isolates from Hefei, 6 from Anqing, 3 from Huaibei, 2 from Fuyang, 2 from Huainan, 2 from Maanshan, 1 from Chuzhou, and 1 from Bengbu (Figure 1).

\section{2 | Phylogenetic analyses of the HA and NA} genes

To better understand the genetic relationships between the H9N2 viruses in Anhui province, we sequenced the complete genomes of
33 representative strains. The genome sequences all shared high sequence similarity at the nucleotide level. For example, the HA and NA genes shared nucleotide identities of $93.2 \%$ to $96.4 \%$ and $93.3 \%$ to $99.3 \%$, respectively.

As described in a previous report, ${ }^{17}$ four stem evolutionary clades of h9.1 to h9.4 were designated to map the HA gene phylogeny. All $\mathrm{HA}$ genes of the viruses in this study belonged to clade 9.4.2.5 represented by $A$ /chicken/Guangxi/55/2005(H9N2), which differed from the A/quail/Hong Kong/G1/1997(H9N2)-like (G1-like, h9.4.1.1) and A/duck/Hong Kong/Y280/1997(H9N2) (Y280-like, H9.4.2.4) viruses prevailing in most Asian countries since 1994 (Figure 2A). The NA genes of all the H9N2 viruses in this study belonged to the A/chicken/Beijing/1/1994(H9N2)-like (BJ/94-like) type and formed four branches together with the G1-like, G9-like, and Y28-like viruses. All NA genes were closely clustered together with those of the Y280-like viruses, forming one group (Figure 2B).

\section{3 | Phylogenetic analyses of the internal genes}

The other six internal genes (polymerase basic protein 2 (PB2), polymerase basic protein 1 (PB1), polymerase acidic protein (PA),
FIGURE 1 Geographical locations of H9N2 avian influenza viruses (AIVs) isolates in Anhui province. The map was designed by Maplnfo Professional 7.0 SCP software

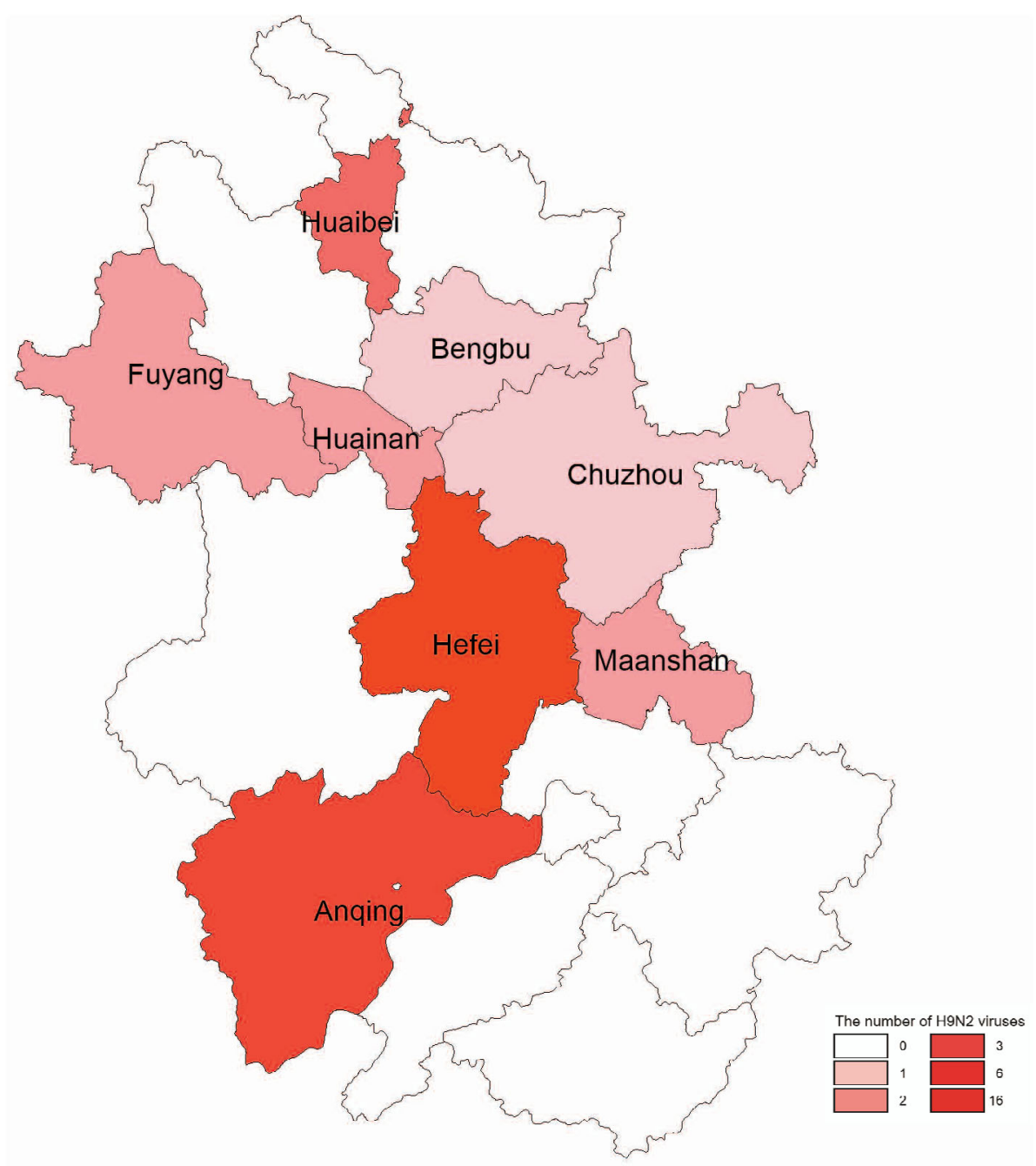




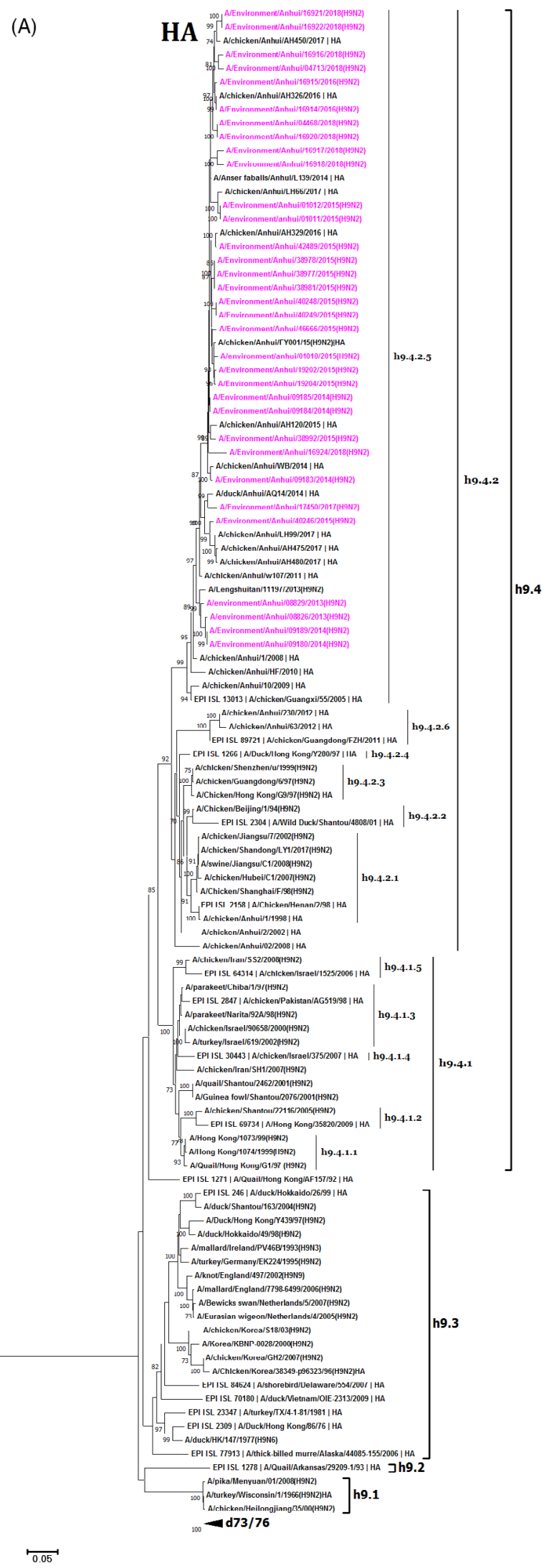

FIGURE 2 Legend on next coloumn. nucleocapsid protein (NP), matrix protein (MP), and nonstructural protein (NS)) shared $94.4 \%$ to $99.6 \%, 95 \%$ to $98.7 \%, 96.1 \%$ to $98 \%, 94 \%$ to $99 \%, 96.6 \%$ to $98.8 \%$, and $94.6 \%$ to $98.9 \%$ nucleotide identity, respectively.

The topological structures of the phylogenetic trees of MP and PB2 were highly similar (Figure $2 \mathrm{C}, \mathrm{H}$ ). All MP and PB2 genes from the strains analyzed in this study belonged to the G1-like lineage and clustered into two phylogenetic subgroups. The phylogenetic tree revealed that the PA, PB1, NP, and NS genes of all the strains clustered together with the $A /$ chicken/Shanghai/F/98-like (F/98-like) viruses (Figure 2D-G). Taken together, these findings indicated that the six internal genes of the H9N2 viruses isolated in Anhui province from 2013 to 2016 had undergone dramatic evolution and reassortment.

To understand the relationship between these internal genes and some novel AIV infections in humans in recent years, we added the internal gene sequences of the early H7N9 (LP and HP), H5N6, $\mathrm{H} 10 \mathrm{~N} 8$, and H7N4 AIVs into the phylogenetic tree. Surprisingly, all the internal genes of the early H7N9 and H10N8 AIVs, even HPAI $\mathrm{H} 7 \mathrm{~N}$, clustered together in one group with the strains analyzed in this study. Intriguingly, the early H5N6 AIVs from Guangdong, Changsha, and Sichuan did not form one branch with these strains, but they did cluster into one group with Anhui H5N6 AIVs. A similar phenomenon occurred for H7N4 AIVs, with only their PB2 genes belonging to the G1-like lineage forming a different subgroup.

\section{4 | Molecular characterization}

All HA genes contained 1742 nucleotides, and most of the H9N2 strains possessed a conserved amino acid sequence motif of $P S R S S R \downarrow G L F$ at the cleavage site, except EnAH 04713/18 (PSKSSR $\downarrow G L F$ motif), which was a typical feature of LPAIVs. We also examined the amino acid substitutions at the receptor-binding site (RBS) of the HA protein, especially $183 \mathrm{~N}$ and $190 \mathrm{~T}$. Among the 33 strains in this study, 29 isolates possessed an A190T mutation,

FIGURE 2 Phylogenetic trees of, A, hemagglutinin (HA), B, neuraminidase (NA), C, matrix protein (MP), D, nucleocapsid protein (NP), E, nonstructural protein (NS), F, polymerase acidic protein (PA), G, polymerase basic protein 1 (PB1), and $\mathrm{H}$, polymerase basic protein 2 (PB2) genes of H9N2 subtype avian influenza viruses (AIVs). Full-length sequences with complete open reading frames were used for the phylogenetic analyses and neighbor-joining $(\mathrm{NJ})$ trees were generated using MEGA 7.0.26. Estimates of the phylogenies were calculated by performing 1000 neighbor-joining bootstrap replicates. The phylogenetic trees of the genes were rooted to A/turkey/ Wisconsin/1966 (A-H). The novel AIVs infected human like H7N9, $\mathrm{H} 10 \mathrm{~N} 8, \mathrm{H} 5 \mathrm{~N} 6$, and H7N4 are shown in light green and the novel HPAI H7N9 AIVs in red. Our 33 isolates from environment samples in Anhui province between 2013 and 2018 are highlighted in pink. The bootstrap values $\geq 70$ are shown 
(B)

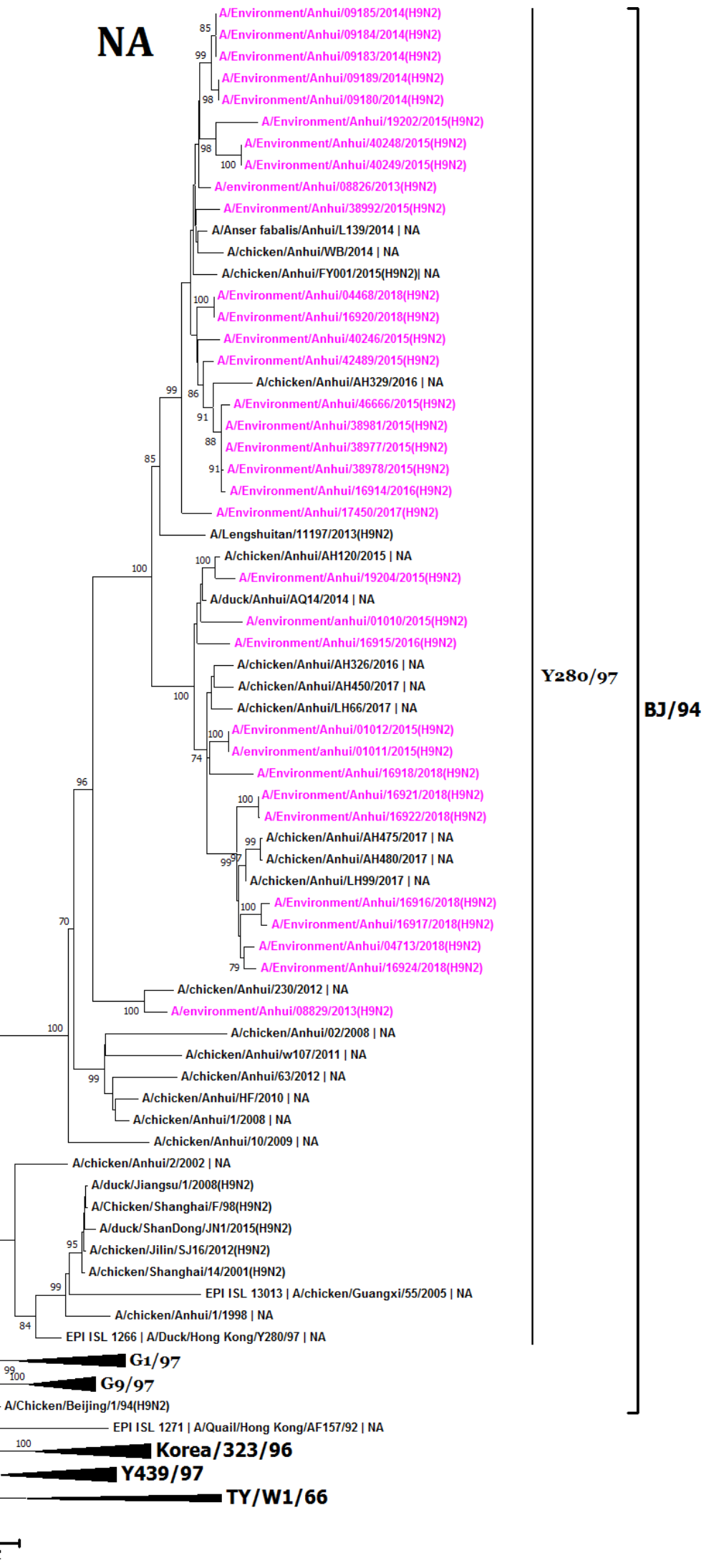

FIGURE 2 (Continued) 
(C)

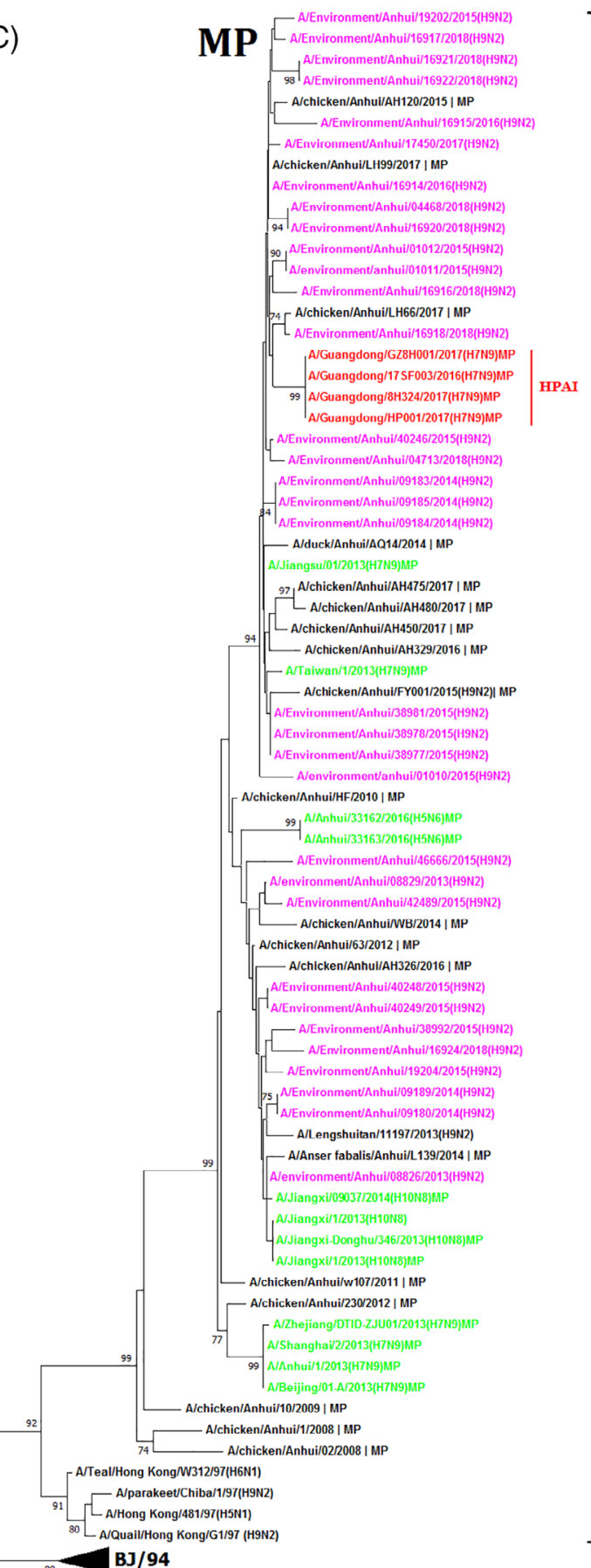

G1/97

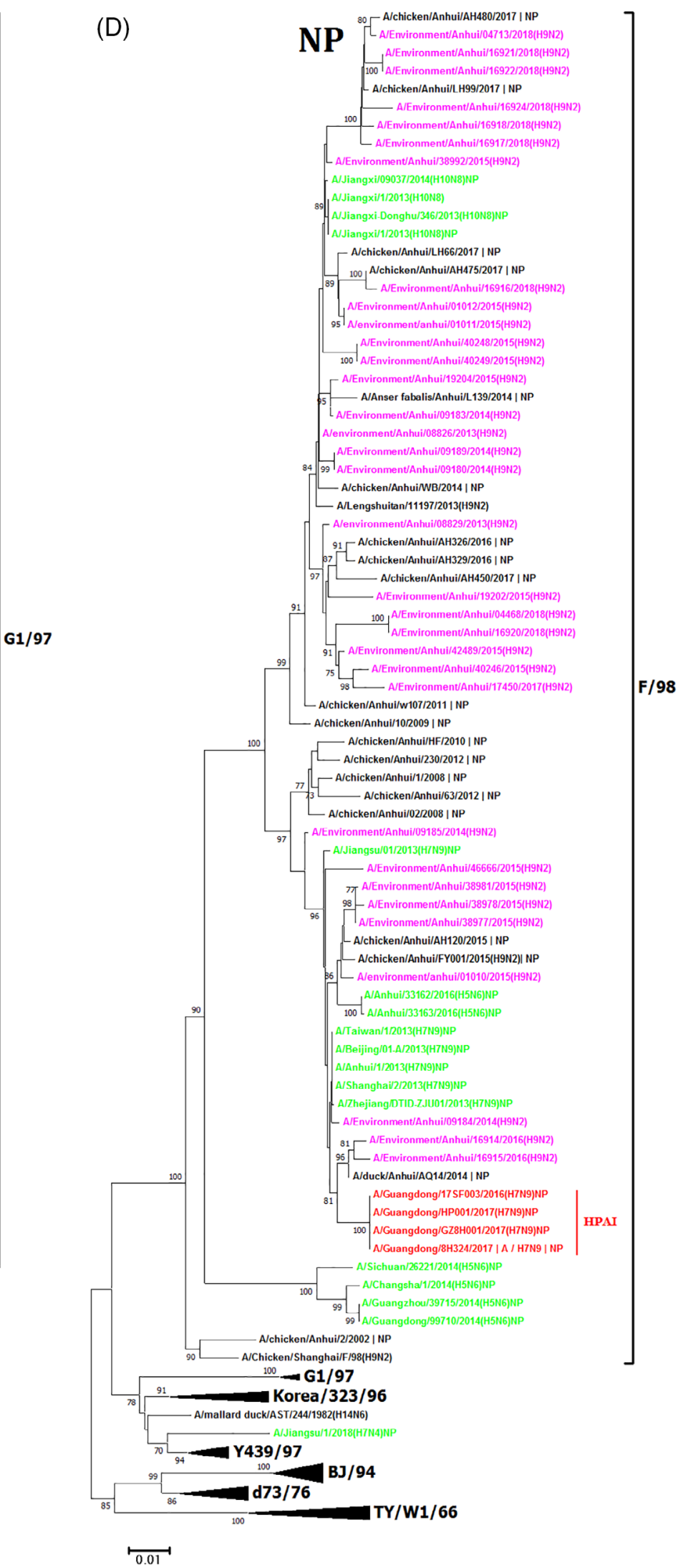

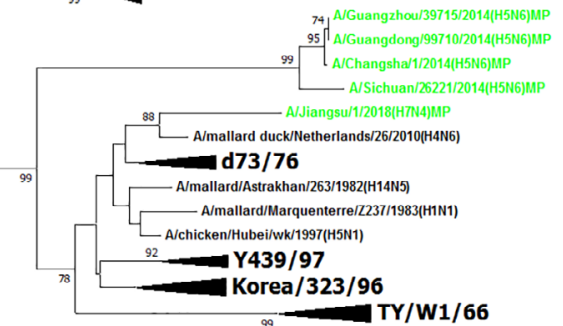

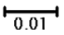

TY/W1/66

FIGURE 2 (Continued) 
(E)

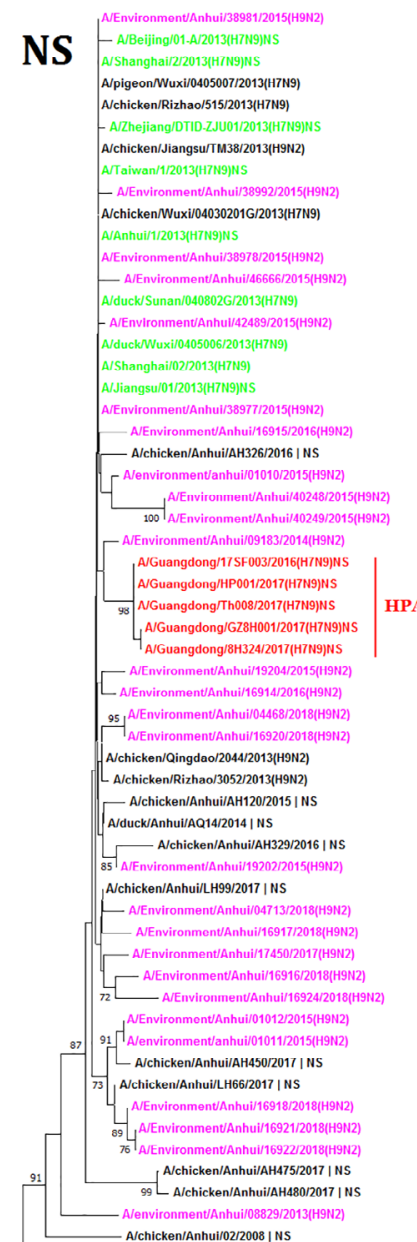

$F / 98$

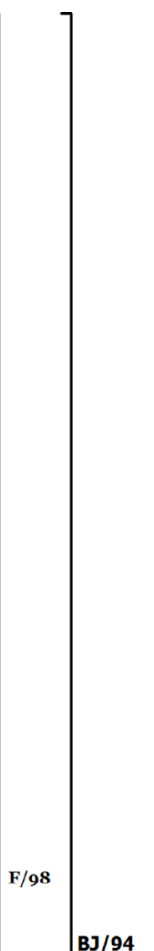

(F)

BJ/94

A/chicken/Anhuir230/2012 |NS

A A/chicken/Anhuil63/2012 | NS

A/Chicken/Anhul/w107/2011 | IS

A/chicken/Anhui//12008 | NS

- A/Lengshuitan/11197/2013(H9N2)

A/EnvironmentAnhul/09184/2014(H9N2)

| A/EnvironmentAnhluilo9185/2014/(H9N2)

A/Anser fabalis/Antu/L13912014 IIIS

9 A/Anhui/33162/2016(H5NG)NS

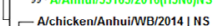

- NEnvironmont/Anhui//10246/2015(H9N-

A NEnvironmont/Anhui///0246/2015(Hond

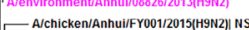

A/chicken/Anhui/fFrod

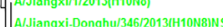

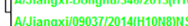

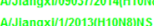

95 A/chicken/Anhui//1/1998 | NS A/chicken/Anhui//1/1998(H9N2)

99 - A/Chicken/Shanghai G9/97

AChicken/Guangdong/11/97/H9N

A/chicken/Guangdong/5/97/(H912)

AChicken/Hong Kong/39/94/H9N2/

A/chicken/Hebeinji2002[H9N2]

G1/97

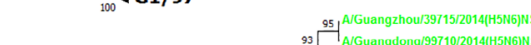

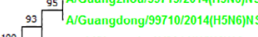
N/Changsha/1/2014/H5

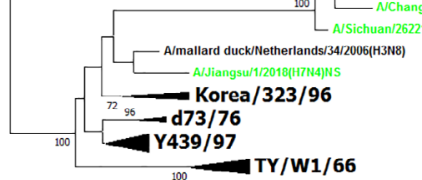

$\mathrm{TY} / \mathrm{W} 1 / 66$

$\longdiv { 0 0 1 0 0 }$

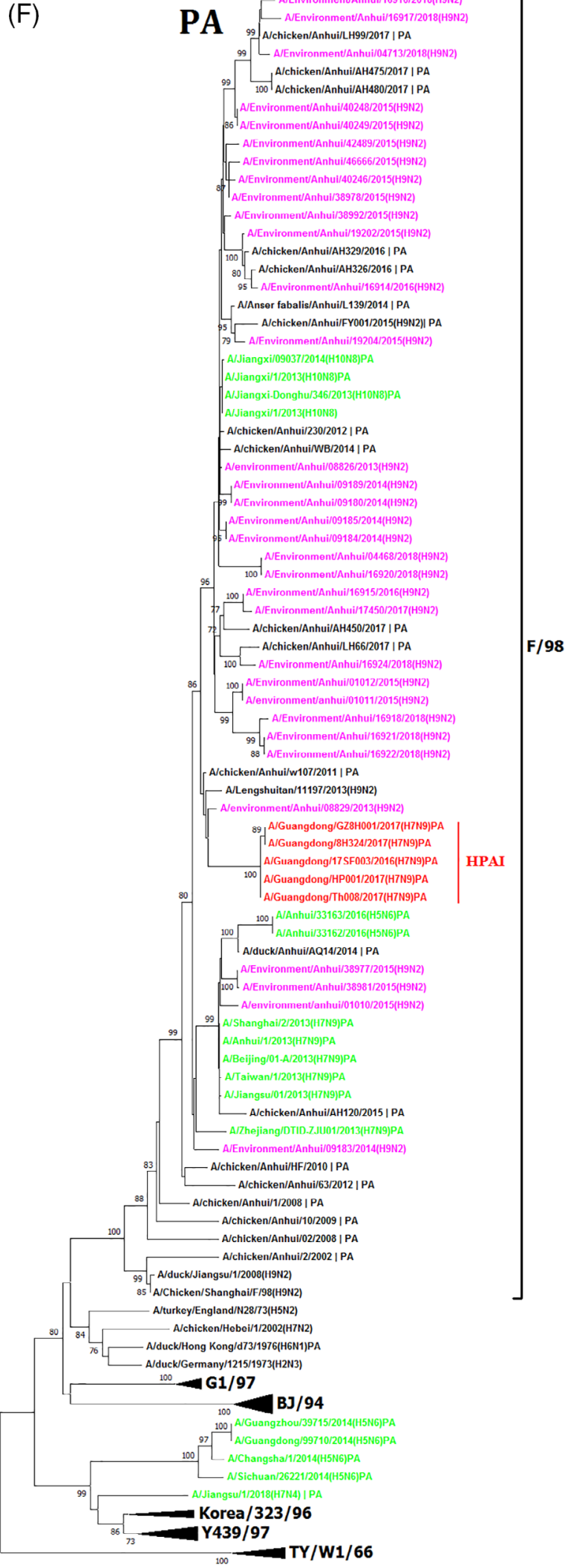

$\longmapsto 0.02$

FIGURE 2 (Continued) 

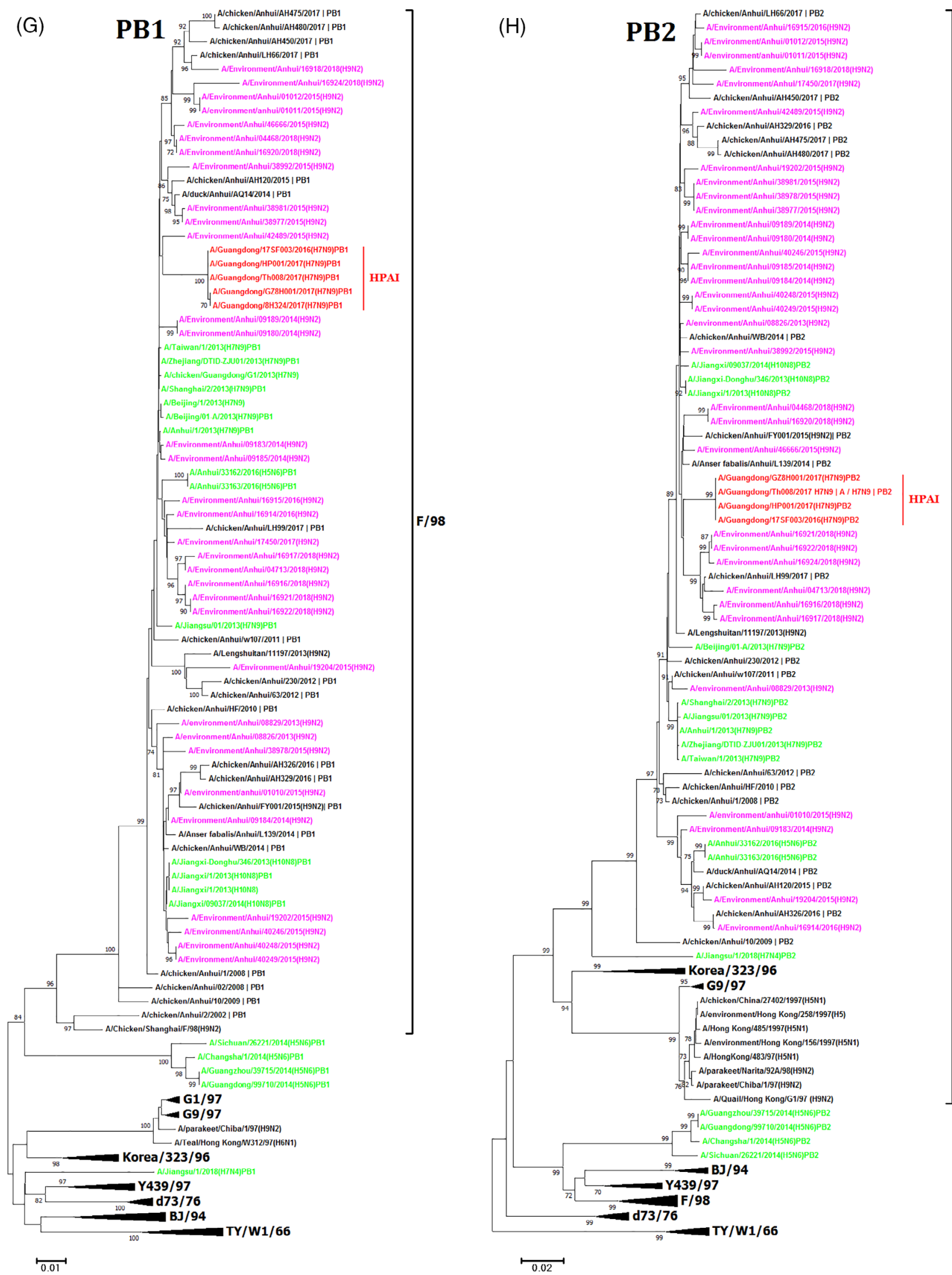

FIGURE 2 (Continued) 


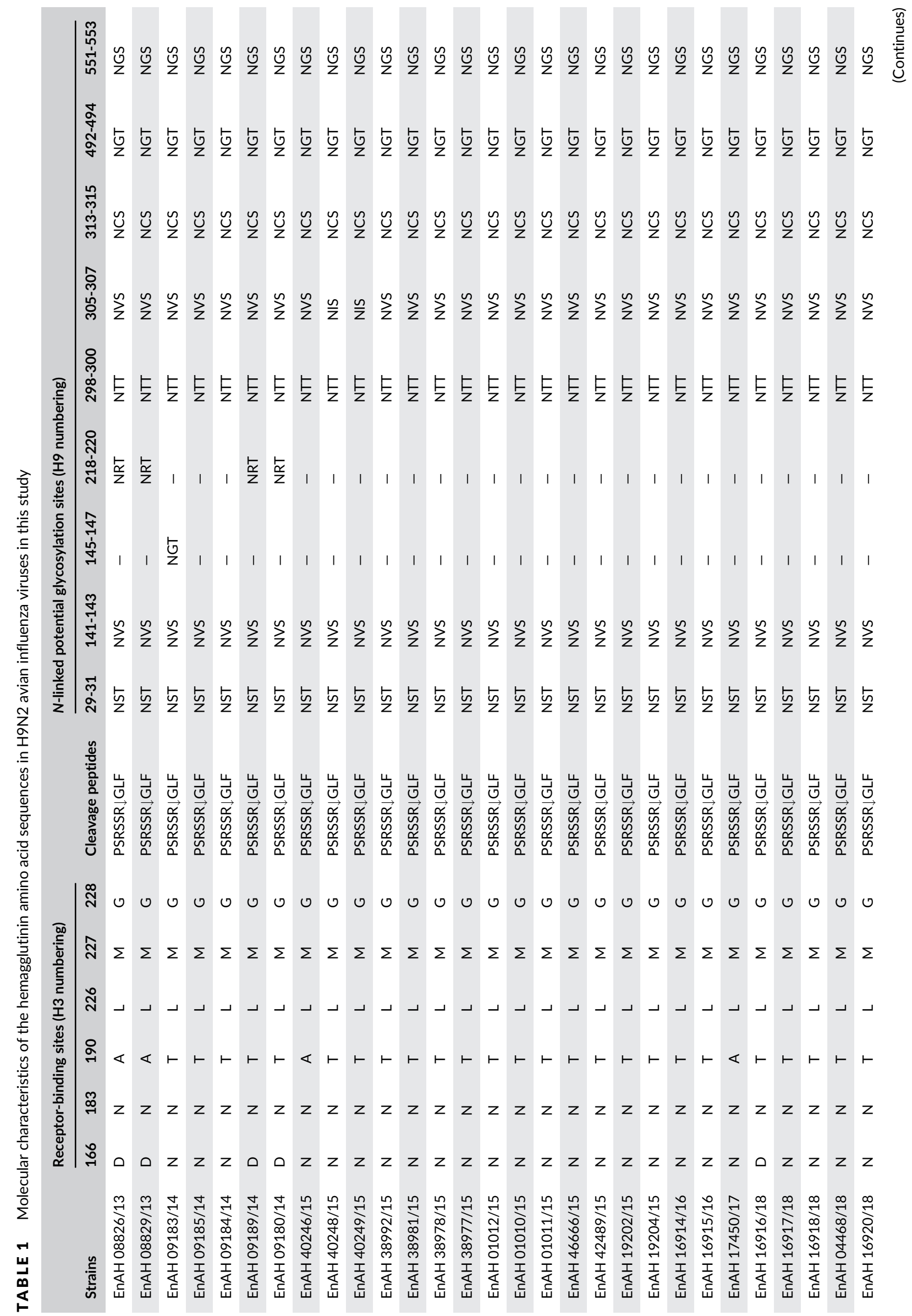




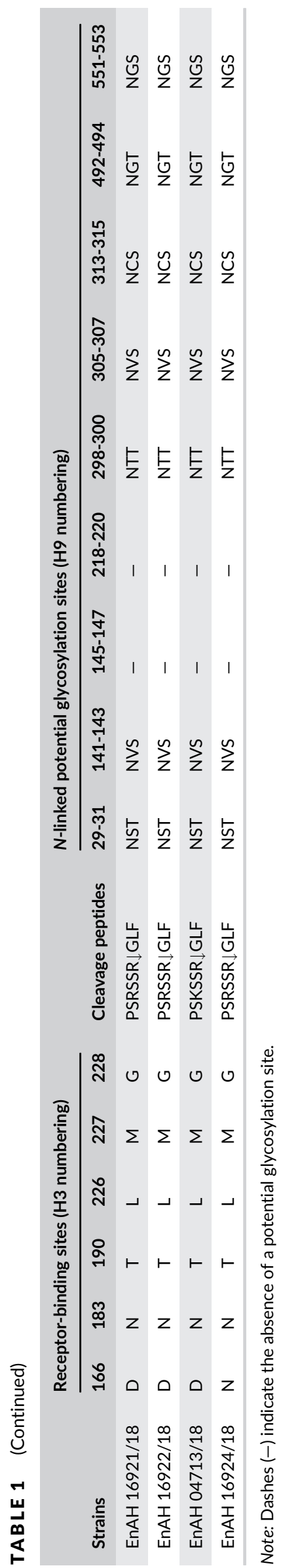

whereas all isolates contained the $\mathrm{H} 183 \mathrm{~N}$ mutation. The amino acids at positions 226 to 228 were "LMG" in all strains. The potential $\mathrm{N}$ linked glycosylation sites (PNLGSs) in the HA proteins of the 33 isolates were predicted by the NetNGlyc 1.0 web server. The results showed that the positions 29, 141, 298, 305, 313, 492, and 551 were conserved. Nonconserved PNLGSs at positions 145 and 218 were located in the HA protein globular domain. Only the EnAH09183/14 virus possessed a PNLGS at position 145, whereas the EnAH 08826/13, EnAH 08829/13, EnAH 09189/14, and EnAH 09180/14 viruses possessed a PNLGS at position 218. The seven PNLGSs in the H9N2 viruses in this study appeared to be relatively stable between 2015 and 2018 (Table 1).

The NA gene from EnAH08829/13 virus did not cluster into one branch with other viruses in this study. The hemadsorbing sites (HBSs) of EnAH08829/13 virus contained "IRNGSRSG" and "DSENW" motifs at positions 366-373 and 399-403, whereas "PQE" was observed in position 431-433 in all the strains. With the exception of EnAH08829/13, the other viruses in this study possessed the "IKNGSRSG" motif at position 366-373. Regarding the active center, the 33 strains possessed six different patterns, with mutations mainly evident at positions 141, 143, 149 , and 155. All of the isolates in this study possessed an amino acid deletion in the stalk region, unlike viruses belonging to the G9-like lineage (Table 2).

Some critical residues in the internal genes were associated with pathogenicity and infectivity; for example, 627E and 701D in PB2 were characteristic of LPAIVs and were observed in 27 of the 33 strains in this study. Residues 100A, 356R, and $409 \mathrm{~N}$ in PA were human adaptation-related markers that were observed in 3 of the 33 strains. All the strains possessed the $1368 \mathrm{~V}$ mutation in PB1 protein, but the H99Y substitution was not detected in any of the strains. The $588 \mathrm{I}$ and $591 \mathrm{~K}$ mutations in PB2 were also not detected in these strains. Residues $95 \mathrm{~K}, 224 \mathrm{~N}$, and $242 \mathrm{~N}$ were found in the M1 protein of 31 strains, and 37A was observed in this protein in all isolates. Residue $21 \mathrm{G}$ was detected in the M2 protein of 26 strains, all of which showed potentially increased infectivity. The NS1-42S mutation was observed in all of the strains analyzed in this study, but 92E was found only in the EnAH 19 204/15 virus. The S31N mutation responsible for amantadine resistance was found in the M2 protein of all H9N2 isolates, but substitutions in the NA protein related to antiviral resistance to neuraminidase inhibitors were not detected (Table 3).

\section{4 | DISCUSSION}

Though investigation of the prevalence of H9N2 virus in lower and middle income countries, either by poultry sero-surveys or by passive sampling, the virus was observed to be present at particularly high rates, especially in LPMs. ${ }^{10}$ LPMs are not only a hub for poultry trading but also a major component of the disease transmission pathway, ${ }^{18}$ contributing to the spread of AIVs among poultry as well as facilitating zoonotic infections. The purpose of this study was to understand the evolution and molecular features of the H9N2 viruses, 


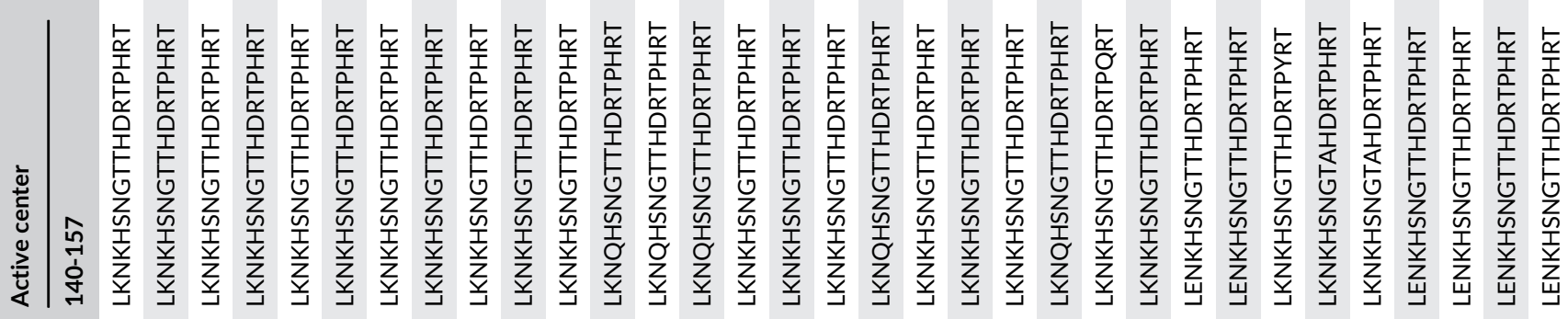

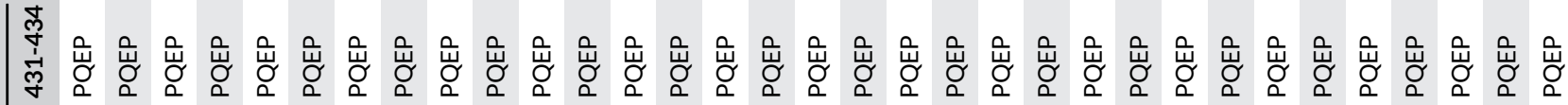

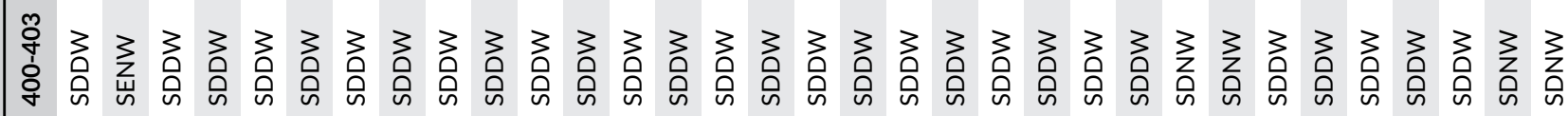

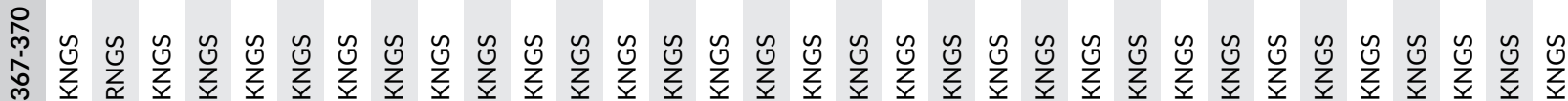

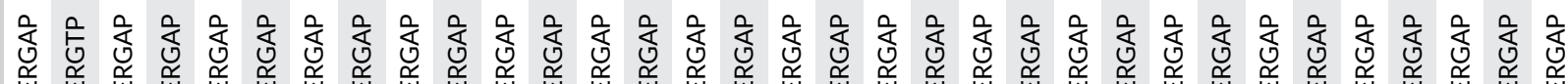

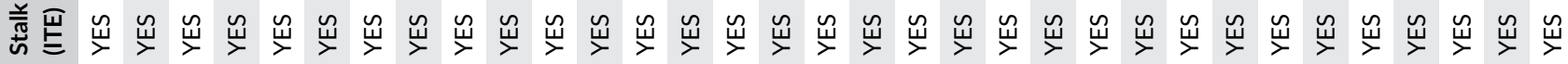
稌

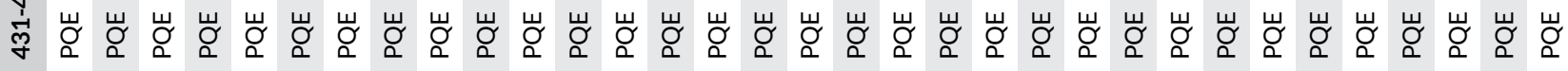
q o 空 U U U U U U U U

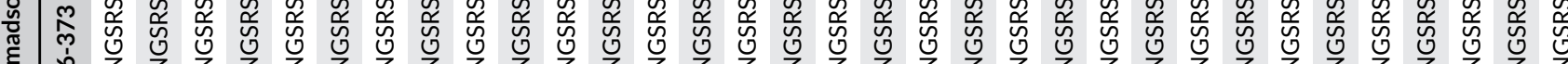

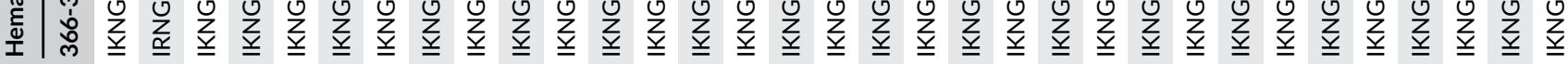
m

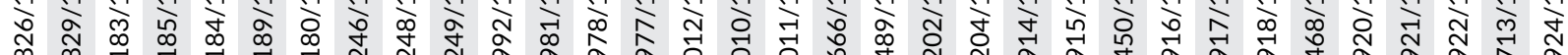

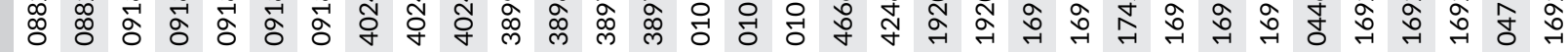

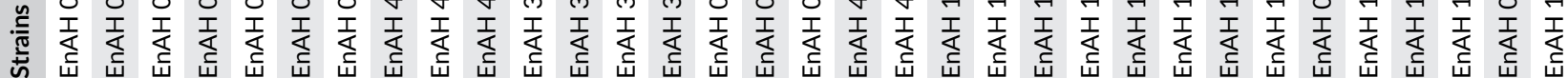


TAB LE 3 Molecular characteristics of the internal amino acid sequences in the H9N2 avian influenza viruses analyzed in this study

\begin{tabular}{|c|c|c|c|c|c|c|c|c|c|c|c|c|c|c|c|c|c|c|}
\hline \multirow[b]{2}{*}{ Strains } & \multicolumn{4}{|l|}{ PA } & \multicolumn{2}{|c|}{ PB1 } & \multicolumn{4}{|l|}{ PB2 } & \multicolumn{4}{|c|}{ M1 } & \multicolumn{2}{|c|}{ M2 } & \multicolumn{2}{|c|}{ NS1 } \\
\hline & 100 & 356 & 409 & 336 & 99 & 368 & 588 & 591 & 627 & 701 & 37 & 95 & 224 & 242 & 21 & 31 & 42 & 92 \\
\hline EnAH 08826/13 & $\mathrm{v}$ & $\mathrm{R}$ & $\mathrm{N}$ & L & $\mathrm{H}$ & $\mathrm{V}$ & $\mathrm{V}$ & Q & E & D & A & $\mathrm{K}$ & $\mathrm{N}$ & $\mathrm{N}$ & G & $\mathrm{N}$ & $\mathrm{s}$ & D \\
\hline EnAH 08829/13 & $\mathrm{v}$ & $\mathrm{R}$ & $\mathrm{N}$ & $\mathrm{L}$ & $\mathrm{H}$ & v & $\mathrm{v}$ & Q & $\mathrm{E}$ & D & A & $\mathrm{K}$ & $\mathrm{N}$ & $\mathrm{N}$ & G & $\mathrm{N}$ & $\mathrm{s}$ & D \\
\hline EnAH 09183/14 & $\mathrm{v}$ & $\mathrm{R}$ & $\mathrm{N}$ & $\mathrm{L}$ & $\mathrm{H}$ & $\mathrm{v}$ & A & Q & $\mathrm{E}$ & D & A & $\mathrm{K}$ & $\mathrm{N}$ & $\mathrm{N}$ & D & $\mathrm{N}$ & $\mathrm{s}$ & D \\
\hline EnAH 09185/14 & $\mathrm{v}$ & $\mathrm{R}$ & $\mathrm{N}$ & $\mathrm{L}$ & $\mathrm{H}$ & $\mathrm{v}$ & $\mathrm{V}$ & Q & E & D & A & $\mathrm{K}$ & $\mathrm{N}$ & $\mathrm{N}$ & D & $\mathrm{N}$ & $\mathrm{s}$ & D \\
\hline EnAH 09184/14 & $\mathrm{v}$ & $\mathrm{R}$ & $\mathrm{N}$ & $\mathrm{L}$ & $\mathrm{H}$ & $\mathrm{v}$ & $\mathrm{v}$ & Q & E & D & A & $\mathrm{K}$ & $\mathrm{N}$ & $\mathrm{N}$ & D & $\mathrm{N}$ & $\mathrm{s}$ & D \\
\hline EnAH 09189/14 & $\mathrm{v}$ & $\mathrm{R}$ & $\mathrm{N}$ & $\mathrm{L}$ & $\mathrm{H}$ & $\mathrm{V}$ & $\mathrm{v}$ & Q & E & D & A & $\mathrm{K}$ & $\mathrm{N}$ & $\mathrm{N}$ & D & $\mathrm{N}$ & _- & _- \\
\hline EnAH 09180/14 & $\mathrm{V}$ & $\mathrm{R}$ & $\mathrm{N}$ & $\mathrm{L}$ & $\mathrm{H}$ & $\mathrm{V}$ & $\mathrm{v}$ & Q & E & D & A & $\mathrm{K}$ & $\mathrm{N}$ & $\mathrm{N}$ & D & $\mathrm{N}$ & - & _ \\
\hline EnAH 40246/15 & $\mathrm{v}$ & $\mathrm{R}$ & $\mathrm{N}$ & $\mathrm{L}$ & $\mathrm{H}$ & V & $\mathrm{v}$ & Q & E & D & A & $\mathrm{K}$ & $\mathrm{N}$ & $\mathrm{N}$ & G & $\mathrm{N}$ & $\mathrm{s}$ & D \\
\hline EnAH 40248/15 & V & $\mathrm{R}$ & $\mathrm{N}$ & $\mathrm{L}$ & $\mathrm{H}$ & v & $\mathrm{v}$ & Q & $\mathrm{E}$ & D & A & $\mathrm{K}$ & $\mathrm{N}$ & $\mathrm{N}$ & G & $\mathrm{N}$ & $\mathrm{s}$ & D \\
\hline EnAH 40249/15 & v & $\mathrm{R}$ & N & L & $\mathrm{H}$ & v & v & Q & E & D & A & K & N & N & G & N & $S$ & D \\
\hline EnAH 38992/15 & v & $\mathrm{R}$ & N & L & $\mathrm{H}$ & v & v & Q & $\mathrm{E}$ & D & A & $\mathrm{K}$ & N & $\mathrm{K}$ & G & $\mathrm{N}$ & $\mathrm{s}$ & D \\
\hline EnAH 38981/15 & A & $\mathrm{R}$ & N & $\mathrm{L}$ & $\mathrm{H}$ & v & v & Q & $\mathrm{E}$ & D & A & K & N & N & G & N & $S$ & D \\
\hline EnAH 38978/15 & $\mathrm{v}$ & $\mathrm{R}$ & N & L & $\mathrm{H}$ & v & v & Q & E & $\mathrm{D}$ & A & K & N & N & G & $\mathrm{N}$ & $\mathrm{s}$ & D \\
\hline EnAH 38977/15 & A & $\mathrm{R}$ & $\mathrm{N}$ & $\mathrm{L}$ & $\mathrm{H}$ & $\mathrm{v}$ & $\mathrm{v}$ & Q & $\mathrm{E}$ & D & A & $\mathrm{K}$ & $\mathrm{N}$ & $\mathrm{N}$ & G & $\mathrm{N}$ & $\mathrm{s}$ & D \\
\hline EnAH 01012/15 & v & $\mathrm{R}$ & N & L & $\mathrm{H}$ & v & v & Q & $\mathrm{E}$ & D & A & K & N & N & G & N & $S$ & D \\
\hline EnAH 01010/15 & A & $\mathrm{R}$ & N & $\mathrm{L}$ & $\mathrm{H}$ & v & A & Q & E & D & A & K & N & N & G & N & $\mathrm{s}$ & D \\
\hline EnAH 01011/15 & V & $\mathrm{R}$ & $\mathrm{N}$ & $\mathrm{L}$ & $\mathrm{H}$ & v & $\mathrm{v}$ & Q & $\mathrm{E}$ & D & A & $\mathrm{K}$ & $\mathrm{N}$ & $\mathrm{N}$ & G & $\mathrm{N}$ & $\mathrm{s}$ & D \\
\hline EnAH 46666/15 & v & $\mathrm{R}$ & N & L & $\mathrm{H}$ & v & v & $\mathrm{Q}$ & $\mathrm{E}$ & D & A & K & N & N & G & N & $S$ & D \\
\hline EnAH 42489/15 & $\mathrm{v}$ & $\mathrm{R}$ & N & L & $\mathrm{H}$ & v & v & Q & $\mathrm{E}$ & D & A & $\mathrm{K}$ & $\mathrm{N}$ & N & D & N & $\mathrm{s}$ & D \\
\hline EnAH 19202/15 & v & $\mathrm{R}$ & N & L & $\mathrm{H}$ & v & v & Q & E & D & A & K & N & N & G & N & $\mathrm{S}$ & D \\
\hline EnAH 19204/15 & $\mathrm{v}$ & $\mathrm{R}$ & N & $\mathrm{L}$ & $\mathrm{H}$ & v & A & Q & E & $\mathrm{D}$ & A & $\mathrm{K}$ & N & N & G & $\mathrm{N}$ & $\mathrm{s}$ & E \\
\hline EnAH 16914/16 & v & $\mathrm{R}$ & $\mathrm{N}$ & $\mathrm{L}$ & $\mathrm{H}$ & v & A & Q & $\mathrm{E}$ & D & A & $\mathrm{K}$ & $\mathrm{N}$ & N & G & $\mathrm{N}$ & $S$ & D \\
\hline EnAH 16915/16 & v & $\mathrm{R}$ & N & L & $\mathrm{H}$ & v & v & Q & E & D & A & K & N & N & v & N & $\mathrm{S}$ & D \\
\hline EnAH 17450/17 & $\mathrm{v}$ & $\mathrm{R}$ & $\mathrm{N}$ & $\mathrm{L}$ & $\mathrm{H}$ & v & $\mathrm{v}$ & Q & $\mathrm{E}$ & D & A & $\mathrm{K}$ & $\mathrm{N}$ & $\mathrm{N}$ & G & $\mathrm{N}$ & $\mathrm{s}$ & D \\
\hline EnAH 16916/18 & $\mathrm{v}$ & $\mathrm{R}$ & N & L & $\mathrm{H}$ & v & v & Q & v & D & A & K & N & N & G & N & $S$ & D \\
\hline EnAH 16917/18 & v & $\mathrm{R}$ & N & L & $\mathrm{H}$ & v & v & Q & v & D & A & K & N & N & G & N & 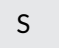 & D \\
\hline EnAH 16918/18 & $\mathrm{v}$ & $\mathrm{R}$ & N & L & $\mathrm{H}$ & v & $\mathrm{v}$ & Q & $\mathrm{E}$ & D & A & $\mathrm{K}$ & $\mathrm{N}$ & N & G & $\mathrm{N}$ & $S$ & D \\
\hline EnAH 04468/18 & v & $\mathrm{R}$ & N & M & $\mathrm{H}$ & v & A & Q & E & D & A & K & N & N & G & N & $\mathrm{s}$ & D \\
\hline EnAH 16920/18 & $\mathrm{v}$ & $\mathrm{R}$ & $\mathrm{N}$ & M & $\mathrm{H}$ & $\mathrm{v}$ & A & Q & E & D & A & $\mathrm{K}$ & $\mathrm{N}$ & $\mathrm{N}$ & G & $\mathrm{N}$ & $\mathrm{s}$ & D \\
\hline EnAH 16921/18 & v & $\mathrm{R}$ & N & L & $\mathrm{H}$ & v & v & Q & v & D & A & K & $\mathrm{N}$ & N & G & $\mathrm{N}$ & $\mathrm{s}$ & D \\
\hline EnAH 16922/18 & v & $\mathrm{R}$ & N & L & $\mathrm{H}$ & v & v & Q & v & D & A & K & N & N & G & N & $\mathrm{s}$ & D \\
\hline EnAH 04713/18 & $\mathrm{v}$ & $\mathrm{R}$ & $\mathrm{N}$ & $\mathrm{L}$ & $\mathrm{H}$ & v & v & Q & v & D & A & $\mathrm{K}$ & $\mathrm{N}$ & $\mathrm{N}$ & G & $\mathrm{N}$ & $\mathrm{s}$ & D \\
\hline EnAH 16924/18 & $\mathrm{v}$ & $\mathrm{R}$ & $\mathrm{N}$ & $\mathrm{L}$ & $\mathrm{H}$ & $\mathrm{V}$ & $\mathrm{v}$ & $\mathrm{Q}$ & $\mathrm{v}$ & D & A & $\mathrm{K}$ & $\mathrm{N}$ & $\mathrm{K}$ & G & $\mathrm{N}$ & $\mathrm{s}$ & D \\
\hline
\end{tabular}

which were constantly circulating in LPMs in Anhui province between 2013 and 2018.

Phylogenetic analysis of the surface HA genes indicated that the lineage h9.4.2.5 was predominant in 2013-2018 in Anhui province. Although environmental strains belonging to h9.4.2.6 were not identified in this study, two strains isolated from chickens clustered into the 9.4.2.6 lineage, which is well established in southern China. The frequent live poultry trade aids the co-circulation of h9.4.2.5 and h9.4.2.6 viruses in Anhui. G1-like PB2 and M genes combined with the genetic backbone of $F / 98$-like viruses were the predominant form of the six internal genes in the strains analyzed in this study. H9N2 subtype AIVs in China have evolved into diversified clusters and genotypes, according to previous research, ${ }^{9}$ and viruses isolated from the environment in this study were designated as genotype $\mathrm{S}$ (generally equivalent to genotype G57). The genotype S H9N2 AIVs were mainly prevalent in the Yangtze River Delta region in eastern China, and Anhui province is located within this area. Evidence has shown that genotype $\mathrm{S}$ exhibits greater infectivity than the other genotypes and has been predominant since 2010 across China, causing a significant threat to the poultry industry. ${ }^{2}$

To control and eradicate both the H7N9 low and highly pathogenic viruses, the $\mathrm{H} 5 / \mathrm{H} 7$ bivalent inactivated vaccine was used to 
protect chickens and ducks from infection. This intervention decreased the prevalence of H7N9 viruses in poultry and humans, confirming that the vaccination of poultry played an important role in preventing the spread of H7N9 virus. However, from our research it is clear that all internal genes of the early H7N9, H5N6(Anhui), and H10N8 AIVs, including HPAI H7N9, were clustered into one group together with the strains analyzed in the present study. These strains isolated from the environment originated from the LPMs in Anhui province, where HPAI H7N9 and H10N8 outbreaks have not occurred. H9N2 AIVs exhibited wide antigenic variability, donating internal genes to other AIVs. ${ }^{19}$ Therefore, if immune-escape $\mathrm{H} 5$ or $\mathrm{H} 7$ AIVs emerge, it is possible that highly pathogenic H7N9 or H5Nx AIVs may reappear. Moreover, high genetic compatibility was found between H9N2 and H1N1pdm(2009) viruses, and reassortment with $\mathrm{H} 3 \mathrm{~N} 2$ is possible, potentially leading to the gain of respiratory transmissibility. ${ }^{3}$ Our study showed that the absence or presence of PNLGSs and key amino acid mutations in RBSs, such as Q226L, may affect receptor affinity. ${ }^{20}$ The N166D mutation in the HA, which appeared in the strains isolated in 2018 in this study, may contribute to the failure of H9N2 vaccination in the field. ${ }^{21}$ In this study, the $95 \mathrm{~K}, 224 \mathrm{~N}$, and $242 \mathrm{~N}$ residues in the $\mathrm{M} 1$ protein and $21 \mathrm{G}$ in the M2 protein may all increase AIV infectivity. ${ }^{22}$ Taken together, our findings indicate that most viral isolates from the environment in Anhui province possessed the ability to increase the affinity for mammals and enhance infectivity and transmission.

In summary, we systematically analyzed H9N2 environmental isolates from Anhui province from 2013 to 2018 . Phylogenetic analysis indicated that h9.4.2.5-like H9N2 viruses were predominant during 2013-2018. Additionally, these viruses had undergone dramatic reassortment and evolution, resulting in wide-ranging genetic diversity. The potentially acquired characteristics of increased affinity for mammals and enhanced infectivity and transmission among viral isolates are worthy of close attention.

\section{ACKNOWLEGMENT}

We would like to thank Dr Wang Dayan for useful discussion.

\section{CONFLICT OF INTEREST}

The authors declare no conflicts of interest.

\section{AUTHOR CONTRIBUTIONS}

Conceptualization: Jun He, Shuxia Zhang, Guizhen Wu

Data curation: Jun He, Shuxia Zhang, Lan He

Formal analysis: Jun He, Jun-Ling Yu, Meng Zhu

Investigation: Jia-Bing Wu, Bin Su, Shuxia Zhang

Methodology: Jun He, Shuxia Zhang, Lei Gong

Software: Jia Liu, Sai Hou

Writing - original draft preparation: Jun He, Shuxia Zhang

Writing - review and editing: Jun He, Shuxia Zhang

All authors have read and approved the final version of the manuscript.
Jun He had full access to all of the data in this study and takes complete responsibility for the integrity of the data and the accuracy of the data analysis.

\section{TRANSPARENCY STATEMENT}

The corresponding author, Jun He, affirms that this manuscript is an honest, accurate, and transparent account of the study being reported; that no important aspects of the study have been omitted; that any discrepancies from the study as planned have been explained.

\section{DATA AVAILABILITY STATEMENT}

The authors confirm that the data supporting the findings of this study are available within the article (and/or) its supplementary material.

\section{REFERENCES}

1. Guan $\mathrm{Y}$, Shortridge KF, Krauss S, Webster RG. Molecular characterization of H9N2 influenza viruses: were they the donors of the "internal" genes of H5N1 viruses in Hong Kong? Proc Natl Acad Sci U S A. 1999;96:9363-9367.

2. Pu J, Wang S, Yin Y, et al. Evolution of the H9N2 influenza genotype that facilitated the genesis of the novel H7N9 virus. Proc Natl Acad Sci U S A. 2015;112:548-553.

3. Sun Y, Liu J. H9N2 influenza virus in China: a cause of concern. Protein Cell. 2015;6:18-25.

4. Khan SU, Anderson BD, Heil GL, Liang S, Gray GC. A systematic review and meta-analysis of the seroprevalence of influenza $A(H 9 N 2)$ infection among humans. J Infect Dis. 2015;212:562-569.

5. Lin YP, Shaw M, Gregory V, et al. Avian-to-human transmission of H9N2 subtype influenza A viruses: relationship between H9N2 and H5N1 human isolates. Proc Natl Acad Sci U S A. 2000;97:9654-9658.

6. Zhang P, Tang Y, Liu X, et al. Characterization of H9N2 influenza viruses isolated from vaccinated flocks in an integrated broiler chicken operation in eastern China during a 5 year period (1998-2002). J Gen Virol. 2008;89:3102-3112.

7. Park KJ, Kwon HI, Song MS, et al. Rapid evolution of low-pathogenic H9N2 avian influenza viruses following poultry vaccination programmes. J Gen Virol. 2011;92:36-50.

8. Sun $\mathrm{Y}, \mathrm{Pu} J$, Fan $\mathrm{L}$, et al. Evaluation of the protective efficacy of a commercial vaccine against different antigenic groups of H9N2 influenza viruses in chickens. Vet Microbiol. 2012;156:193-199.

9. Gu M, Xu L, Wang X, Liu X. Current situation of H9N2 subtype avian influenza in China. Vet Res. 2017;48:49.

10. Peacock THP, James J, Sealy JE, Iqbal M. A global perspective on H9N2 avian influenza virus. Viruses. 2019;11:620.

11. Sealy JE, Fournie G, Trang PH, et al. Poultry trading behaviours in Vietnamese live bird markets as risk factors for avian influenza infection in chickens. Transbound Emerg Dis. 2019;66:2507-2516. https:// doi.org/10.1111/tbed.13308

12. Bi $\mathrm{Y}$, Chen $\mathrm{Q}$, Wang $\mathrm{Q}$, et al. Genesis, evolution and prevalence of H5N6 avian influenza viruses in China. Cell Host Microbe. 2016;20: 810-821.

13. Chen $\mathrm{H}$, Yuan $\mathrm{H}$, Gao R, et al. Clinical and epidemiological characteristics of a fatal case of avian influenza A H10N8 virus infection: a descriptive study. Lancet. 2014;383:714-721.

14. Wu A, Su C, Wang D, et al. Sequential reassortments underlie diverse influenza H7N9 genotypes in China. Cell Host Microbe. 2013;14: 446-452.

15. Zou S, Zhang Y, Li X, et al. Molecular characterization and receptor binding specificity of H9N2 avian influenza viruses based on poultry- 
related environmental surveillance in China between 2013 and 2016. Virology. 2019;529:135-143.

16. Kumar S, Stecher G, Tamura K. MEGA7: molecular evolutionary genetics analysis version 7.0 for bigger datasets. Mol Biol Evol. 2016; 33:1870-1874.

17. Jiang W, Liu S, Hou G, et al. Chinese and global distribution of $\mathrm{H} 9$ subtype avian influenza viruses. PLoS One. 2012;7:e52671.

18. Fournie G, Guitian J, Desvaux S, et al. Interventions for avian influenza A (H5N1) risk management in live bird market networks. Proc Natl Acad Sci U S A. 2013;110:9177-9182.

19. Wu H, Peng X, Peng X, et al. Genetic and molecular characterization of H9N2 and H5 avian influenza viruses from live poultry markets in Zhejiang Province, eastern China. Sci Rep. 2015;5:17508.

20. Teng Q, Xu D, Shen W, et al. A single mutation at position 190 in hemagglutinin enhances binding affinity for human type sialic acid receptor and replication of H9N2 avian influenza virus in mice. J Virol. 2016;90:9806-9825.

21. Jin F, Dong X, Wan Z, et al. A single mutation N166D in hemagglutinin affects antigenicity and pathogenesis of H9N2 avian influenza virus. Viruses. 2019;11:709.
22. Pu J, Sun $\mathrm{H}, \mathrm{Qu} Y$, et al. M gene reassortment in H9N2 influenza virus promotes early infection and replication: contribution to rising virus prevalence in chickens in China. J Virol. 2017;91: e02055-e02016.

\section{SUPPORTING INFORMATION}

Additional supporting information may be found online in the Supporting Information section at the end of this article.

How to cite this article: Zhang S, Yu J-L, He L, et al. Molecular characteristics of the H9N2 avian influenza viruses in live poultry markets in Anhui Province, China, 2013 to 2018. Health Sci Rep. 2021;4:e230. https://doi.org/10.1002/ hsr2.230 